\title{
Processamento e estabilidade de uma bebida de caju e yacon durante o armazenamento sob refrigeração
}

\author{
Processing and stability of a beverage composed of cashew apple and yacon under \\ refrigerated storage
}

\author{
Ana Paula Dionisio"*, Nedio Jair Wurlitzer ${ }^{1}$, Claudia Oliveira Pinto', Talita de Souza Goes², \\ Maria de Fatima Borges' ${ }^{1}$, Idila Maria da Silva Araújo' \\ ${ }^{1}$ Embrapa Agroindústria Tropical, Fortaleza/CE - Brasil \\ 2 Universidade Federal do Ceará (UFC), Departamento de Ciência e Tecnologia de Alimentos, Fortaleza/CE - Brasil
}

\section{*Corresponding Author}

Ana Paula Dionisio, Embrapa Agroindústria Tropical, Rua Dra. Sara Mesquita, 2270, CEP: 60511-110, Fortaleza/CE - Brasil, e-mail: ana.dionisio@embrapa.br

Cite as: Processing and stability of a beverage composed of cashew apple and yacon under refrigerated storage. Braz. J. Food Technol., v. 21, e2016189, 2018

\section{Resumo}

O objetivo do presente trabalho foi avaliar a estabilidade de uma bebida de caju e yacon durante o armazenamento sob refrigeração. A bebida, composta por polpa de caju e extrato de yacon (proporção $1: 1, \mathrm{v} / \mathrm{v}$ ), foi pasteurizada a $85^{\circ} \mathrm{C}$ por 90 segundos e armazenada sob refrigeração $\left(5^{\circ} \mathrm{C}\right)$. No tempo inicial e a cada 45 dias do período de estocagem, foram determinados os teores de compostos bioativos (ácido ascórbico - AA e polifenóis extraíveis totais - PET), a atividade antioxidante total (AAT), os sólidos solúveis totais (SST), a acidez titulável (AT), o pH e a cor (L*, a* e b*). Após 225 dias de estocagem, a bebida apresentou diminuição expressiva da sua AAT, medida pelo método FRAP (Ferric Reducing Antioxidant Power), de aproximadamente $22 \%$, assim como houve queda nas concentrações de AA e PET, em torno de 20 e $16 \%$, respectivamente. A bebida atendeu ao padrão estabelecido pela legislação brasileira para coliformes a $45^{\circ} \mathrm{C}$ e Salmonella sp. (ausência/25 mL); porém, em 135 dias de armazenamento, a bebida apresentou contagem de bolores e leveduras superior a $10^{4} \mathrm{UFC} / \mathrm{mL}$. Neste sentido, embora a bebida tenha apresentado níveis consideráveis de compostos bioativos e AAT durante os 225 dias de armazenamento refrigerado $\left(5^{\circ} \mathrm{C}\right)$, recomenda-se que o produto seja armazenado por até 90 dias sob refrigeração $\left(5^{\circ} \mathrm{C}\right)$, período em que a bebida manteve seus componentes bioativos e boa qualidade microbiológica e sensorial.

Palavras-chave: Smallanthus sonchifolius; Estocagem; Qualidade.

\section{Abstract}

The objective of the present study was to evaluate the stability of a beverage produced with cashew apple and yacon during refrigerated storage. The beverage, composed of cashew pulp and yacon extract (ratio 1: 1, $\mathrm{v} / \mathrm{v}$ ), was pasteurized at $85{ }^{\circ} \mathrm{C}$ for 90 seconds and stored at $5{ }^{\circ} \mathrm{C}$. The following components were evaluated at zero time (after processing and packaging) and every 45 days during the storage period: the bioactive compound contents (ascorbic acid (AA), total extractable polyphenols (PET), total antioxidant activity (AAT), total soluble solids, titratable acidity (AT), pH and colour $\left(L^{*}, a{ }^{*}\right.$ and $\left.b{ }^{*}\right)$. After 225 days of storage, the beverage presented a 22\% decrease in AAT as analysed by the FRAP method (Ferric Reducing Antioxidant Power), as well as a drop in the AA and PET concentrations of around 20 and $16 \%$, respectively. The beverage complied with the microbiological standard established by Brazilian legislation for coliforms at $45^{\circ} \mathrm{C}$ and Salmonella sp. (absence/25 mL), but after 135 days storage, the beverage had a yeast and mould count greater than $10^{4} \mathrm{CFU} / \mathrm{mL}$. Thus although the beverage presented considerable levels of bioactive compounds and AAT during the 225 days of refrigerated storage $\left(5^{\circ} \mathrm{C}\right)$, it is recommended that it be stored for up to 90 days under refrigeration $\left(5^{\circ} \mathrm{C}\right)$, considering the microbiological, sensorial quality and maintenance of its bioactive components during this period.

Keywords: Smallanthus sonchifolius; Storage; Quality. 


\section{Introdução}

O caju é o fruto obtido do cajueiro (Anacardium occidentale L.), que é uma planta tropical nativa do Brasil, com uma importância socioeconômica considerável para a Região Nordeste do Brasil, devido principalmente à comercialização da sua castanha (CAMELO, 2014). O caju apresenta características importantes do ponto de vista nutricional, contendo cerca de 156 a 378 mg de vitamina C, 14,70 mg de cálcio, 32,55 mg de fósforo e 0,57 mg de ferro, por $100 \mathrm{~mL}$ de suco (EMBRAPA, 2004). Possui também elevadas concentrações de polifenóis, como ácidos anacárdicos (TEDONG et al., 2010; OLIVEIRA et al., 2012), que estão sendo pesquisados por envolvimento na prevenção de distúrbios, como câncer, dano oxidativo, inflamação e obesidade (HEMSHEKHAR et al., 2012).

O yacon (Smallanthus sonchifolius) é uma raiz tuberosa de origem andina. Sua polpa apresenta textura crocante e sabor semelhante ao de frutas, como pera e melão. Ao contrário de outras raízes que armazenam energia na forma de amido, o yacon armazena carboidratos na forma de frutanos, especialmente do tipo fruto-oligossacarídeos - FOS (CAMPOS et al., 2012). Estes carboidratos são prebióticos reconhecidos por estimularem de forma seletiva o crescimento ou a atividade de um número limitado de bactérias benéficas do intestino grosso, como lactobacilos e bifidobactérias (SOUSA et al., 2015). Além disso, também estão presentes, no yacon, alguns polifenóis específicos, destacando-se o ácido clorogênico, que são compostos bioativos de grande importância no metabolismo humano, que, além de apresentarem ação antioxidante, têm sido apontados no envolvimento da modulação da síndrome metabólica (CAMPOS et al., 2012; DELGADO et al., 2013; MA et al., 2015).

Recentemente, a Embrapa Agroindústria Tropical desenvolveu uma bebida mista de yacon e caju com potencial antioxidante e prebiótico (DIONÍSIO et al., 2015), com efeitos comprovados através de ensaios in vitro e in vivo. Em testes com ratos induzidos ao diabetes por injeção intraperitoneal com aloxana, os animais apresentaram diminuição da glicemia, elevação do potencial antioxidante endógeno e aumento dose-dependente dos microrganismos benéficos (lactobacilos) do material cecal (VIEIRA, 2014).

Embora a bebida desenvolvida tenha sido testada in vitro e in vivo, ainda não foram realizados ensaios sobre a estabilidade dessa bebida frente ao armazenamento refrigerado. Testes de estabilidade são extremamente importantes para comprovação e garantia ao consumidor de que o produto mantém suas características desejáveis e que não sofreu alterações significativas que possam comprometer sua funcionalidade, qualidade e segurança.

Diante disso, o objetivo deste trabalho foi avaliar a estabilidade, através de análises físicas, químicas, físico-químicas, microbiológicas e sensoriais, de uma bebida mista de caju (polpa) e yacon (extrato) pasteurizada $\left(85^{\circ} \mathrm{C}\right.$ por 90 segundos) e armazenada sob refrigeração $\left(5^{\circ} \mathrm{C}\right)$.

\section{Material e métodos}

\subsection{Processamento da bebida prebiótica de caju e yacon}

Foram utilizadas raízes de yacon in natura e polpa de caju, adquiridas no mercado local de Fortaleza - CE. A polpa de caju foi armazenada sob congelamento $\left(-18^{\circ} \mathrm{C}\right)$, até o momento do uso, e as raízes foram processadas imediatamente, para obtenção do extrato de yacon. Para o processamento das raízes de yacon, utilizou-se a metodologia reportada por Dionísio et al. (2013b). Para tanto, as raízes foram sanitizadas em água clorada (200ppm de cloro ativo), descascadas manualmente e cortadas em cubos de $1 \mathrm{~cm}^{3}$, os quais foram imediatamente imersos em uma solução de ácido cítrico (2,40\%, por oito minutos) e, em seguida, drenados para retirada da água. O yacon foi, então, triturado em triturador doméstico (Mondial, Brasil), com lâminas tipo faca de aço inoxidável e peneira (0,5 mm), para separação dos sólidos. O material sólido foi descartado e a fração líquida foi denominada de "extrato de yacon", sendo mantida sob congelamento $\left(-18^{\circ} \mathrm{C}\right)$, até o momento do uso.

Para a formulação da bebida, a polpa de caju foi misturada ao extrato de yacon (proporção 1:1, v/v) e, então, adicionada de 0,07\% de edulcorante Stevia, conforme descrito por Dionísio et al. (2013a). Após formulação, a bebida foi submetida ao tratamento térmico $\left(85^{\circ} \mathrm{C}\right.$ por 90 segundos), utilizando-se um trocador tubular Armfield FT74X, e foi efetuado o enchimento a quente em garrafas de vidro de $200 \mathrm{~mL}$, previamente higienizadas com cloro (200 ppm). As garrafas foram fechadas com tampa plástica rosqueável, mantidas deitadas por dois minutos e, então, resfriadas em água $\left(20^{\circ} \mathrm{C} \pm 2{ }^{\circ} \mathrm{C}\right)$. A bebida embalada foi armazenada sob refrigeração $\left(5^{\circ} \mathrm{C} \pm 2^{\circ} \mathrm{C}\right)$ até o momento das análises.

\subsection{Estabilidade química, física, microbiológica e sensorial da bebida de caju e yacon}

Na avaliação da estabilidade, a bebida foi submetida a análises físicas, químicas, microbiológicas e sensoriais, realizadas no tempo zero e a cada 45 dias de armazenamento. As análises físicas, químicas e físico-químicas foram realizadas até diminuição acentuada da atividade antioxidante total (AAT) e dos compostos bioativos do produto, sendo considerada como limitante uma redução de $20 \%$ da atividade inicial. As análises sensoriais, por sua vez, ocorreram após análise dos resultados das análises microbiológicas da bebida, sendo, portanto, limitadas por esses resultados. 


\subsubsection{Análises físicas e químicas}

Os teores de sólidos solúveis ( ${ }^{\circ}$ Brix) e o pH (leitura direta das amostras em potenciômetro) foram determinados diretamente na bebida. A acidez titulável (AT) foi realizada titulando-se a amostra com solução de $\mathrm{NaOH} 0,10 \mathrm{M}$. A cor foi determinada através de um colorímetro, obtendo-se os parâmetros $L^{*}$, $a^{*} e b^{*}$. Polifenóis extraíveis totais (PET) foram determinados por meio de reação com o reagente de Folin-Ciocalteu, utilizando-se uma curva padrão de ácido gálico como referência, conforme metodologia descrita por Larrauri et al. (1997). O teor de ácido ascórbico foi quantificado utilizando-se método de titulometria com solução de DFI (2,6 diclorofenolindofenol a 0,02\%), até coloração rósea clara permanente, de acordo com Strohecker e Henning (1967). A atividade antioxidante total (AAT) foi determinada por meio de três métodos distintos, com modificações, sendo: (a) método de captura do radical 2,2'-azinobis (3-etilbenzotiazolina-6-ácido sulfônico) - ABTS (MILLER et al., 1993); (b) pela captura do radical livre 2,2-diphenyl-1-picril-hidrazil - DPPH (BRAND-WILIAMS et al., 1995), e (c) método de redução do ferro - FRAP (Ferric Reducing Antioxidant Power) (BENZIE; STRAIN, 1996). Todas as análises realizadas seguiram as modificações propostas por Rufino et al. (2010).

\subsubsection{Análises microbiológicas}

Como indicadores de estabilidade da bebida, foram realizadas as contagens de fungos filamentosos e leveduras, coliformes a $45^{\circ} \mathrm{C}$ e E. coli, além de pesquisa de Salmonella sp., seguindo a metodologia descrita no manual FDA's Bacteriological Analytical Manual (APHA, 2001; ANDREWS et al., 2014). Os resultados foram expressos como UFC/g (para E.colie fungos filamentosos e leveduras), ausência/mL (para coliformes a $45^{\circ} \mathrm{C}$ ) e ausência/25 mL (para Salmonella sp.).

\subsubsection{Análise sensorial}

Foram aplicados os testes afetivos de aceitação global e aceitação dos atributos aparência, aroma e sabor, utilizando-se a escala hedônica estruturada mista de nove pontos, variando de "Desgostei muitíssimo"=1 a "Gostei muitíssimo" $=9$. No total, foram recrutados 50 consumidores de suco de frutas, não treinados, que realizaram os testes em cabines individuais climatizadas $\left(24^{\circ} \mathrm{C}\right)$, sob iluminação controlada (luz branca, fluorescente) e equipadas com terminais de computadores para registro/coleta de dados por meio do software FIZZ (versão 2.3, Biosystemes, France). Os protocolos dos testes sensoriais foram previamente aprovados pelo Comitê de Ética em Pesquisa da Universidade Estadual do Ceará, registrados sob n. ${ }^{\circ} 11044529-5$.

\subsubsection{Análise estatística}

Os dados experimentais obtidos foram avaliados por análise de regressão, utilizando-se o programa estatístico SAS (SAS Use's Guide: Version 6.11. Edition 1996, Institute Inc, n. C. USA), e os gráficos e equações, com o uso de planilha eletrônica Excel.

\section{Resultados e discussão}

As Tabelas 1 e 2 apresentam os valores médios para as análises físicas e químicas durante o armazenamento da bebida, bem como o coeficiente de determinação $\left(\mathrm{R}^{2}\right)$ e o $p$-valor.

No decorrer do armazenamento, foram observados um aumento da acidez titulável (AT) e uma diminuição do pH. A AT é um importante parâmetro de qualidade de um produto, em que reações envolvidas na decomposição, como hidrólise, oxidação e fermentação, geram compostos ácidos que, por consequência, aumentam a acidez do meio (CHIM et al., 2013; CARDOSO et al., 2013). A determinação do $\mathrm{pH}$, por sua vez, é importante, devido à sua influência na palatabilidade, no desenvolvimento de microrganismos, na escolha da temperatura do tratamento térmico e na seleção dos produtos de higienização e de aditivos, entre outros aspectos (CHAVES, 1993). Considerando-se estes parâmetros, os resultados mostraram que, durante o armazenamento da bebida, ocorreu um decréscimo nos seus valores de $\mathrm{pH}$, a partir do primeiro tempo de armazenamento, enquanto a acidez se elevou neste mesmo

Tabela 1. Propriedades físicas e químicas da bebida de caju e yacon, durante 225 dias sob refrigeração $\left(5^{\circ} \mathrm{C}\right)$.

\begin{tabular}{|c|c|c|c|c|c|c|c|c|c|}
\hline \multirow{2}{*}{\multicolumn{2}{|c|}{ Parâmetro }} & \multicolumn{8}{|c|}{ Armazenamento (dias) } \\
\hline & & 0 & 45 & 90 & 135 & 180 & 225 & $\mathbf{R}^{2}$ & $p$ \\
\hline \multicolumn{2}{|c|}{$\begin{array}{l}\text { Sólidos solúveis totais } \\
\qquad\left({ }^{\circ} \mathrm{Brix}\right)\end{array}$} & $9,60 \pm 0,00$ & $9,55 \pm 0,09$ & $9,53 \pm 0,06$ & $9,53 \pm 0,06$ & $9,40 \pm 0,15$ & $9,50 \pm 0,00$ & 0,27 & 0,0908 \\
\hline \multicolumn{2}{|c|}{$\mathrm{pH}$} & $3,96 \pm 0,02$ & $3,91 \pm 0,01$ & $3,83 \pm 0,01$ & $3,79 \pm 0,01$ & $3,76 \pm 0,01$ & $3,75 \pm 0,01$ & 0,97 & $<0,0001$ \\
\hline \multicolumn{2}{|c|}{$\begin{array}{l}\text { Acidez total titulável } \\
\text { (\% ácido cítrico) }\end{array}$} & $0,29 \pm 0,00$ & $0,28 \pm 0,00$ & $0,28 \pm 0,00$ & $0,31 \pm 0,00$ & $0,29 \pm 0,00$ & $0,34 \pm 0,00$ & 0,65 & 0,0004 \\
\hline \multirow{3}{*}{ Cor } & $L^{*}$ & $49,56 \pm 0,58$ & $51,17 \pm 1,42$ & $41,79 \pm 1,35$ & $48,44 \pm 0,57$ & $56,92 \pm 5,75$ & $51,79 \pm 0,32$ & 0,23 & 0,1353 \\
\hline & $a^{*}$ & $-3,78 \pm 0,07$ & $-4,06 \pm 0,24$ & $-4,03 \pm 0,04$ & $-3,26 \pm 0,07$ & $-4,08 \pm 0,07$ & $-4,13 \pm 0,01$ & 0,13 & 0,3552 \\
\hline & $\mathbf{b}^{*}$ & $19,8 \pm 0,74$ & $20,83 \pm 0,30$ & $15,6 \pm 0,22$ & $21,79 \pm 0,10$ & $21,18 \pm 0,18$ & $20,58 \pm 0,20$ & 0,12 & 0,3847 \\
\hline
\end{tabular}


Processamento e estabilidade de uma bebida de caju e yacon durante o armazenamento sob refrigeração

Dionisio, A. P. et al.

Tabela 2. Atividade antioxidante total (AAT) e compostos bioativos da bebida de caju e yacon, durante 225 dias sob refrigeração $\left(5^{\circ} \mathrm{C}\right)$.

\begin{tabular}{|c|c|c|c|c|c|c|c|c|c|}
\hline \multirow{2}{*}{\multicolumn{2}{|c|}{ Parâmetro }} & \multicolumn{8}{|c|}{ Armazenamento (dias) } \\
\hline & & 0 & 45 & 90 & 135 & 180 & 225 & $\mathbf{R}^{2}$ & $p$ \\
\hline \multirow{3}{*}{ 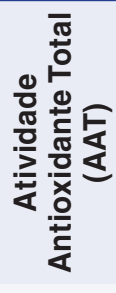 } & $\begin{array}{c}\text { DPPH } \\
\text { (g suco/g DPPH) }\end{array}$ & $1859,86 \pm 58,2$ & $1845,01 \pm 33,5$ & $2100,54 \pm 56,8$ & $1865,41 \pm 38,90$ & $1869,37 \pm 101,3$ & $1924,27 \pm 50,5$ & 0,09 & 0,4950 \\
\hline & $\begin{array}{c}\text { FRAP } \\
\left(\mu \mathrm{M} \mathrm{Fe}_{2} \mathrm{SO}_{4} / \mathrm{g}\right)\end{array}$ & $15,85 \pm 0,42$ & $15,48 \pm 1,15$ & $14,60 \pm 0,09$ & $14,59 \pm 0,34$ & $13,05 \pm 0,71$ & $12,43 \pm 0,46$ & 0,82 & $<0,0001$ \\
\hline & $\begin{array}{c}\text { ABTS } \\
(\mu \mathrm{M} \text { Trolox/g) }\end{array}$ & $3,58 \pm 0,32$ & $3,80 \pm 0,19$ & $3,74 \pm 0,09$ & $3,61 \pm 0,04$ & $3,46 \pm 0,29$ & $3,68 \pm 0,09$ & 0,03 & 0,7730 \\
\hline \multirow{2}{*}{ 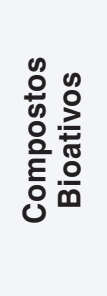 } & $\begin{array}{c}\text { Ácido ascórbico } \\
(\mathrm{mg} / 100 \mathrm{~g})\end{array}$ & $70,31 \pm 1,31$ & $60,21 \pm 1,24$ & $57,36 \pm 2,45$ & $56,98 \pm 0,20$ & $56,32 \pm 0,38$ & $56,32 \pm 0,78$ & 0,89 & $<0,0001$ \\
\hline & $\begin{array}{c}\text { Polifenóis } \\
\text { extraíveis totais } \\
\text { (mg ácido gálico } \\
\text { equivalente/ } 100 \mathrm{~g} \text { ) }\end{array}$ & $64,57 \pm 5,16$ & $60,63 \pm 2,35$ & $68,57 \pm 3,62$ & $61,47 \pm 0,45$ & $52,20 \pm 3,47$ & $54,00 \pm 2,29$ & 0,52 & 0,0039 \\
\hline
\end{tabular}

período, com valores estatisticamente significativos (ver Tabela 1).

Os sólidos solúveis totais (SST) incluem importantes compostos responsáveis pelo sabor e pela consequente aceitação por parte dos consumidores, sendo os açúcares e os ácidos orgânicos os mais importantes. Embora um decréscimo nos valores de SST tenha ocorrido desde o início do armazenamento, essa variação não foi estatisticamente significativa $(p>0,05)$. Desta forma, pode-se concluir que a estocagem não interferiu na manutenção da qualidade final da bebida, com relação a este parâmetro.

Com relação à cor da bebida de caju e yacon, não se observou diferenças significativas $(p>0,05)$ para todos os parâmetros analisados $\left(L^{*}, a^{*} e b^{*}\right)$. A cor, expressa no sistema CIELAB $\left(L^{*}, a^{*}\right.$ e $\left.b^{*}\right)$, é definida por três eixos perpendiculares; o eixo " $\mathrm{L}^{*}$ " (luminosidade) varia do preto (0\%) ao branco (100\%); o eixo "a*", do verde (-) ao vermelho (+), e o eixo "b*", do azul (-) ao amarelo $(+)$. Considerando-se esse sistema, as características cromáticas da bebida demonstraram que ela se localiza dentro do primeiro quadrante, apresentando valores positivos de $a^{*} e b^{*}$, ou seja, a cor vermelha e amarela, respectivamente. Com relação ao período de estocagem, observou-se que os valores para estes parâmetros não apresentaram efeitos significativos $(p>0,05)$.

Para determinação da atividade antioxidante total (AAT) de um alimento, diversos métodos podem ser utilizados. Estes métodos apresentam distintos mecanismos, que podem ser baseados na captura do radical peroxila (ORAC, por exemplo), no poder de redução do metal (FRAP, por exemplo), na captura do radical orgânico (ABTS, DPPH, por exemplo), na quantificação de produtos formados durante a peroxidação de lipídios (co-oxidação do $\beta$-caroteno, por exemplo), dentre outros mecanismos.
Os métodos ABTS, FRAP, DPPH e ORAC são alguns dos mais usados (RUFINO et al., 2007). Porém, recomenda-se que pelo menos dois destes ensaios sejam combinados para fornecer uma informação confiável da AAT de um alimento (RUFINO et al., 2010). Considerando-se tal recomendação, três destes métodos foram utilizados para acompanhar a vida de prateleira da bebida de caju e yacon: FRAP, ABTS e DPPH.

Os resultados apresentados na Tabela 2 mostram que, dentre os três métodos utilizados para análise de AAT da bebida, apenas o método FRAP apresentou significância estatística $(p<0,0001)$, apresentando uma redução de aproxidamente $22 \%$ da AAT ao final do período de armazenamento. A redução da AAT da bebida de caju e yacon pode estar associada a perdas de seus componentes bioativos, como ácido ascórbico (AA) e os polifenóis extraíveis totais (PET). O caju é reconhecido pelo seu elevado conteúdo de AA, chegando a apresentar cerca de cinco vezes mais o conteúdo deste componente do que a laranja (LOPES et al., 2012). Além disso, também apresenta elevadas concentrações de polifenóis, assim como o yacon, reconhecido este pelo elevado conteúdo de ácido clorogênico. Com relação ao AA e aos PET da bebida de caju e yacon, pode-se observar que ambos os componentes analisados apresentaram decréscimo ao longo do período de armazenamento, chegando a uma redução de aproximadamente $20 \%$ e $16 \%$, ao final dos 225 dias de estocagem, para AA e PET, respectivamente.

Diversos trabalhos reportam o efeito do processamento térmico e de diferentes condições de armazenamento na estabilidade do AA e de PET, em sucos de frutas. Lavinas et al. (2006) avaliaram a estabilidade do AA de suco de caju armazenado sob diferentes condições de estocagem e verificaram uma redução no teor médio de 
Processamento e estabilidade de uma bebida de caju e yacon durante o armazenamento sob refrigeração

Dionisio, A. P. et al.

AA de $6,57 \%, 4,44 \%$ e 2,70\%, respectivamente, nos sucos armazenados em temperatura ambiente, sob refrigeração e sob congelamento durante $24 \mathrm{~h}$. Os autores concluíram que o armazenamento à temperatura ambiente foi crítico para a estabilidade do AA, ocorrendo as maiores perdas vitamínicas. Com relação ao PET, Dionísio et al. (2016) avaliaram a estabilidade de uma bebida de frutas tropicais e yacon, durante o armazenamento refrigerado, e verificaram uma perda significativa de polifenóis, chegando a 20\% no final do período de estocagem (225 dias). Lima et al. (2008), avaliando a estabilidade de uma bebida mista à base de água de coco e acerola, verificaram uma completa degradação das antocianinas totais (uma classe dos polifenóis), ao final de 180 dias à temperatura ambiente $\left(28^{\circ} \mathrm{C}\right)$, mostrando claramente o efeito da temperatura na estabilidade destes compostos bioativos.

De acordo com o pH, os alimentos são classificados como de baixa acidez ( $\mathrm{pH}>4,5)$, ácidos ( $\mathrm{pH}$ de 4,0 a 4,5) e muito ácidos $(\mathrm{pH}<4,0)$. Essa classificação se baseia no pH mínimo para a multiplicação e produção de toxina do Clostridium botulinum ( $\mathrm{pH}=4,5)$, e no $\mathrm{pH}$ mínimo para a multiplicação da grande maioria das bactérias $(\mathrm{pH}=4,0)$. Dessa forma, a bebida foi considerada como "muito ácida" ou "ácida", o que favoreceu sua estabilidade microbiológica e, consequentemente, a sua segurança de consumo. Baseando-se nessa classificação, é definido o tratamento térmico ideal para o produto que se deseja obter, de forma que seja seguro o seu consumo e estável durante a vida útil. Na Tabela 3, são apresentados os valores médios $(n=5)$ para as análises microbiológicas durante o armazenamento da bebida, em temperatura de refrigeração $\left(5^{\circ} \mathrm{C}\right)$.

Os resultados das análises microbiológicas demonstraram que, durante o período de estocagem, a bebida apresentou ausência para coliformes a $45^{\circ} \mathrm{C}$ e Salmonella sp.; desta forma, atendeu aos critérios de segurança microbiológica preconizados pela legislação brasileira para suco (BRASIL, 2001). Porém, a partir de 135 dias, observou-se um crescimento acentuado de leveduras e bolores (> 104 UFC/g). Levando-se em consideração os resultados de contagem de bolores e leveduras da bebida, optou-se por realizar a análise sensorial somente até 90 dias. Até este período, os resultados demonstraram que, para a aceitação da bebida, não foram encontradas diferenças significativas $(p>0,05)$ entre os resultados obtidos ao longo dos 90 dias de armazenamento refrigerado $\left(5^{\circ} \mathrm{C}\right)$, com notas que oscilaram de 6,41 a 6,27, na escala hedônica de nove pontos, ficando entre "gostei ligeiramente" e "gostei moderadamente" (Figura 1).

Desta forma, em posse dos resultados das análises microbiológicas e sensoriais do produto, considerou-se que a bebida de caju e yacon apresenta estabilidade até 90 dias de armazenamento refrigerado $\left(5^{\circ} \mathrm{C}\right)$, mesmo que os componentes bioativos e AAT tenham se mantido relativamente estáveis até 225 dias de estocagem, quando

Tabela 3. Qualidade microbiológica da bebida de caju e yacon armazenada sob refrigeração $\left(5^{\circ} \mathrm{C}\right)$.

\begin{tabular}{cccc} 
Armazenamento (dias) & $\begin{array}{c}\text { Coliformes fecais e E.coli } \\
\text { (UFC/mL) }\end{array}$ & $\begin{array}{c}\text { Fungos filamentosos e } \\
\text { leveduras (UFC/mL) }\end{array}$ & $\begin{array}{c}\text { Salmonella sp. } \\
\text { (Ausência/25 g) }\end{array}$ \\
1 & 0,0 & 0,0 & Ausência \\
45 & 0,0 & 0,0 & Ausência \\
90 & 0,0 & 0,0 & Ausência \\
135 & 0,0 & $1,2 \times 10^{4}$ & Ausência \\
\hline
\end{tabular}

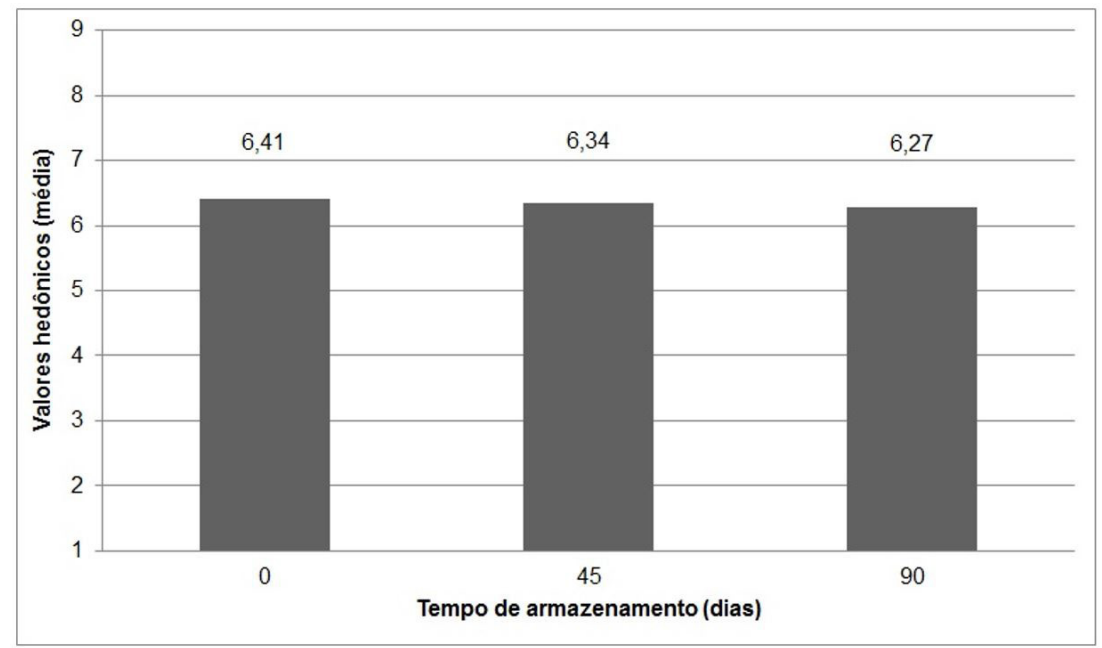

Figura 1. Valores hedônicos médios de aceitação sensorial da bebida de caju e yacon armazenada sob refrigeração $\left(5{ }^{\circ} \mathrm{C}\right)$. 
Processamento e estabilidade de uma bebida de caju e yacon durante o armazenamento sob refrigeração Dionisio, A. P. et al.

pasteurizada a $85{ }^{\circ} \mathrm{C}$ por 90 segundos. Sugere-se que outros binômios 'tempo $\times$ temperatura' sejam estudados, a fim de viabilizar o aumento da vida útil do produto, considerando-se a sua qualidade microbiológica.

\section{Conclusões}

A bebida de caju e yacon, embora tenha apresentado níveis consideráveis de compostos bioativos durante o período de armazenamento refrigerado $\left(5^{\circ} \mathrm{C}\right)$, apresentou como limitante a qualidade microbiológica do produto, devendo ser armazenada por até 90 dias. Sob as condições de processamento (pasteurização $85^{\circ} \mathrm{C} / 90$ segundos) e armazenamento avaliadas $\left(5^{\circ} \mathrm{C}\right)$, a bebida apresentou manutenção de seus componentes bioativos, sem alteração na sua qualidade sensorial e microbiológica nesse período.

\section{Agradecimentos}

Os autores agradecem ao CNPq pelo financiamento da pesquisa.

\section{Referências}

AMERICAN PUBLIC HEALTH ASSOCIATION - APHA. Compendium of methods for the microbiological examination of foods. 4 . ed. Washington: APHA, 2001. $676 \mathrm{p}$.

ANDREWS, W. H.; JACOBSON, A.; HAMMACK, T. S. Salmonella. In: UNITED STATES FOOD DRUG ADMINISTRATION - FDA (Ed.). Bacteriological analytical manual online. 8th ed. Rockville: FDA, 2014. chap. 5. Disponível em: <http://www.cfsan.fda.gov/ ebam/bam-5.html>. Acesso em: 9 dez. 2016.

BENZIE, I. F. F.; STRAIN, J. J. The ferric reducing ability of plasma (FRAP) as a measure of antioxidant power: the FRAP assay. Analytical Biochemistry, v. 239, n. 1, p. 70-76, 1996. PMid:8660627. http://dx.doi.org/10.1006/abio.1996.0292.

BRAND-WILIAMS, W.; CUVELIER, M. E.; BERSET, C. Use of a free radical method to evaluate antioxidant activity. Food Science and Technology, v. 28, p. 25-30, 1995.

BRASIL. Resolução RDC n 12, de 02 de janeiro de 2001. Aprova regulamento técnico sobre os padrões microbiológicos para alimentos. Diário Oficial [da] República Federativa do Brasil, Brasília, DF, 10 jan. 2001.

CAMELO, C. O. Mercado internacional da amêndoa da castanha de caju: um panorama de 2003 a 2012. 2014. 56 f. Monografia (Bacharelado em Gestão do Agronegócio)-Universidade de Brasília, Brasília, 2014.

CAMPOS, D.; BETALLELUZ-PALLARDEL, I.; CHIRINOS, R.; AGUILAR-GALVEZ, A.; NORATTO, G.; PEDRESCHI, R. PEDRESCHI, R. Prebiotic effects of yacon (Smallanthus sonchifolius Poepp. \& Endl), a source of fructooligosaccharides and phenolic compounds with antioxidant activity. Food Chemistry, v. 135, n. 3, p. 1592-1599, 2012. PMid:22953898. http://dx.doi.org/10.1016/j. foodchem.2012.05.088.
CARDOSO, A. M. R.; SANTOS, A. M. S.; ALMEIDA, F. W. B.; AlBUQUERQUE, T. P.; XAVIER, A. F. C.; CAVALCANTI, A. L. Características físico-químicas de sucos de frutas industrializados: estudo in vitro. Odonto, v. 21, n. 41-42, p. 9-17, 2013. http:// dx.doi.org/10.15603/2176-1000/odonto.v21n41-42p9-17.

CHAVES, J. B. P. Noções de microbiologia e conservação de alimentos. 2. ed. Viçosa: Universidade de Viçosa, 1993. 113 p.

CHIM, J. F.; ZAMBIAZI, R. C.; RODRIGUES, R. S. Estabilidade da vitamina $\mathrm{C}$ em néctar de acerola sob diferentes condições de armazenamento. Revista Brasileira de Produção Agroindustrial, v. 15, n. 4, p. 321-327, 2013. http://dx.doi.org/10.15871/15178595/rbpa.v15n4p321-327.

DELGADO, G. T.; TAMASHIRO, W. M.; MARÓSTICA-JUNIOR, M. R.; PASTORE, G. M. Yacon (Smallanthus sonchifolius): a functional food. Plant Foods for Human Nutrition, v. 68, n. 3, p. 222-228, 2013. PMid:23709016. http://dx.doi.org/10.1007/ s11130-013-0362-0.

DIONÍSIO, A. P.; SILVA, L. B. C.; VIEIRA, N. M.; GOES, T. S.; WURLITZER, N. J.; BORGES, M. F.; BRITO, E. S.; IONTA, M.; FIGUEIREDO, R. W. Cashew-apple (Anacardium occidentale L.) and yacon (Smallanthus sonchifolius) functional beverage improve the diabetic state in rats. Food Research International, v. 77, p. 171-176, 2015. http://dx.doi.org/10.1016/j.foodres.2015.07.020.

DIONÍSIO, A. P.; WURLITZER, N. J.; BORGES, M. F.; MODESTO, A. L. G.; ARAUJO, I. M.; PEREIRA, A. C. S.; GOES, T. S.; VIEIRA, N. M.; FIGUEIREDO, R. W. Desenvolvimento de bebida prebiótica de caju e yacon. Fortaleza: Embrapa, 2013a. (Boletim de Pesquisa e Desenvolvimento, 82).

DIONÍSIO, A. P.; WURLITZER, N. J.; VIEIRA, N. M.; GOES, T. S.; MODESTO, A. L. G.; ARAUJO, I. M. Raiz tuberosa de yacon (Smallanthus sonchifolius): obtenção de extrato com manutenção das suas propriedades nutricionais e inativação de enzimas de escurecimento. Fortaleza: Embrapa, 2013b. (Comunicado Técnico, 203).

DIONÍSIO, A. P.; WURLITZER, N. J.; GOES, T. S.; BORGES, M. F.; GARRUTI, D. S.; ARAUJO, I. M. S. Estabilidade de uma bebida funcional de frutas tropicais e yacon (Smallanthus sonchifolius) durante o armazenamento sob refrigeração. Archivos Latinoamericanos de Nutricion, v. 66, p. 148, 2016.

EMPRESA BRASILEIRA DE PESQUISA AGROPECUÁRIA EMBRAPA. Manual de segurança e qualidade para a cultura do caju. Brasília: EMBRAPA/SEDE, 2004. 67 p. (Série Qualidade e Segurança dos Alimentos).

HEMSHEKHAR, M.; SANTHOSH, M. S.; KEMPARAJU, K.; GIRISH, K. Emerging roles of anacardic acid and its derivatives: a pharmacological overview. Basic \& Clicinal Pharmacology \& Toxicology, v. 110, n. 2, p. 122-132, 2012. PMid:22103711. http://dx.doi.org/10.1111/j.1742-7843.2011.00833.x.

LARRAURI, J. A.; RUPÉREZ, P.; SAURA-CALIXTO, F. Effect of drying temperature on the stabilitity of polyphenols and antioxidant 
Processamento e estabilidade de uma bebida de caju e yacon durante o armazenamento sob refrigeração

Dionisio, A. P. et al.

activity of red grape pomace peels. Journal of Agricultural and Food Chemistry, v. 45, n. 4, p. 1390-1393, 1997. http://dx.doi. org/10.1021/jf960282f.

LAVINAS, F. C.; ALMEIDA, N. C.; MIGUEL, M. A. L.; LOPES, M. L. M.; VALENTE-MESQUITA, V. L. Estudo da estabilidade química e microbiológica do suco de caju in natura armazenado em diferentes condições de estocagem. Ciência e Tecnologia de Alimentos, v. 26, n. 4, p. 875-883, 2006. http://dx.doi.org/10.1590/ S0101-20612006000400026.

LIMA, A. S.; MAIA, G. A.; SOUSA, P. H. M.; SILVA, F. V. G.; FIGUEIREDO, E. A. T. Desenvolvimento de bebida mista à base de água de coco e suco de acerola. Ciência e Tecnologia de Alimentos, v. 28, n. 3, p. 683-690, 2008. http://dx.doi.org/10.1590/ S0101-20612008000300026.

LOPES, M. M. A.; MIRANDA, M. R. A.; MOURA, C. F. H.; ENÉAS FILHO, J. Bioactive compounds and total antioxidant capacity of cashew apples (Anacardium occidentale L.) during the ripening of early dwarf cashew clones. Ciência e Agrotecnologia, v. 36, n. 3, p. 325-332, 2012. http://dx.doi.org/10.1590/S141370542012000300008.

MA, Y.; GAO, M.; LIU, D. Chlorogenic acid improves high fat diet-induced hepatic steatosis and insulin resistance in mice. Pharmaceutical Research, v. 32, n. 4, p. 1200-1209, 2015. PMid:25248334. http://dx.doi.org/10.1007/s11095-014-1526-9.

MILLER, N. J.; RICE-EVANS, C.; DAVIES, M. J.; GOPINATHAN, V.; MILNER, A. A novel method for measuring antioxidant capacity and its application to monitoring the antioxidant status in premature neonates. Clinical Science, v. 84, n. 4, p. 407-412, 1993. PMid:8482045. http://dx.doi.org/10.1042/cs0840407.

OLIVEIRA, V. B.; YAMADA, L. T.; FAGG, C. W.; BRANDÃO, M. G. Native foods from Brazilian biodiversity as a source of bioactive compounds. Food Research International, v. 48, n. 1, p. 170-179, 2012. http://dx.doi.org/10.1016/j.foodres.2012.03.011.

RUFINO, M. S. M.; ALVES, R. E.; BRITO, E. S.; MORAIS, S. M.; SAMPAIO, C. G.; PEREZ-JIMENEZ, J.; SAURA-CALIXTO, F. D. Metodologia científica: determinação da atividade antioxidante total em frutas pela captura do radical livre DPPH. Fortaleza: Embrapa, 2007. (Comunicado Técnico, 127).

RUFINO, M. S. M.; ALVES, R. E.; BRITO, E. S.; PEREZ-JIMENEZ, E. S. J.; SAURA-CALIXTO, F.; MANCINI-FILHO, J. Bioactive compounds and antioxidant capacities of 18 nontraditional tropical fruits from Brazil. Food Chemistry, v. 121, n. 4, p. 996-1002, 2010. http://dx.doi.org/10.1016/j.foodchem.2010.01.037.

SOUSA, S.; PINTO, J.; PEREIRA, C.; XAVIER, M. F.; BERTOLDO, P. M. T.; GOMES, A. M.; PINTADO, M. In vitro evaluation of yacon (Smallanthus sonchifolius) tuber flour prebiotic potential. Food and Bioproducts Processing, v. 95, p. 96-105, 2015. http:// dx.doi.org/10.1016/j.fbp.2015.04.003.

STROHECKER, R.; HENNING, H. M. Analisis de vitaminas: métodos comprobados. Madrid: Paz Montalvo, 1967. 428 p.

TEDONG, L.; MADIRAJU, P.; MARTINEAU, L. C.; VALLERAND, D.; ARNASON, J. T.; DESIRE, D. D. P.; LAVOIE, L.; KAMTCHOUING, P.; HADDAD, P. S. L. Hydro-ethanolic extract of cashew tree (Anacardium occidentale) nut and its principal compound, anacardic acid, stimulate glucose uptake in C2C12 muscle cells. Molecular Nutrition \& Food Research, v. 54, n. 12, p. 1753-1762, 2010. PMid:20603833. http://dx.doi.org/10.1002/ mnfr.201000045.

VIEIRA, N. M. Desenvolvimento de bebidas mistas de frutas tropicais e yacon como fonte de oligossacarídeos prebióticos. 2014. 117 f. Dissertação (Mestrado em Ciência e Tecnologia de Alimentos)-Universidade Federal do Ceará, Fortaleza, 2014. 